reassurance to those without ST segment changes is fatuous; it is action and not words which is needed to show a patient that he or she can walk, bicycle, swim, or even tie shoe laces without danger. ST segment behaviour and drop in morale are not related to each other.

Some patients do not want to join formal exercise courses. Most wish to get back to active life, however, and need proper advice about how to do so, whether they have been in hospital or looked after at home. Many hospitals do not provide any exercise rehabilitation facilities for patients with coronary disease, and the doctor in charge of such patients has to give them sensible advice about how to get fitter on their own. This takes time, but it is time well spent. The simplest start is with a walking campaign, and patients need to be told that in the absence of angina, uncomfortable breathlessness, or profound fatigue they are not doing too much. Some patients prefer a routine based on how far they get in their daily walk in a certain time and improve their fitness by going a bit further each day, or by walking a set distance and reducing the time. Once they can achieve four miles an hour with comfort most prefer to proceed to other things such as slow running, swimming, or bicycling. Patients need to be told that exercise should be enjoyable and that sprinting and marathon running are not an essential part of any programme; they often also appreciate knowing that both these activities have been safely performed by patients who have had an infarction. The important feature is to increase the exercise gradually. Symptoms are a reason to cut back on the intensity, and they should be reported if they continue.

Exercise may be beneficial in many chronic illnesses: obesity, diabetes, asthma, coronary disease, hypertension, and probably osteoporosis. ${ }^{1}$ This form of treatment is cheap, not accompanied by side effects other than muscle stiffness, which wears off in time, and it actually makes people feel better. It is surprising how reluctant our profession is to accept this. "Whenever I feel the desire to take exercise I lie down until the feeling passes off," allegedly said for the first time by Bernard Shaw, several American presidents, and innumerable doctors is beginning to sound as silly and outdated as "one for the road."

After a myocardial infarction patients feel very vulnerable and most listen to, and often act on, whatever advice is given. Doctors should be wary about blanket advice on things such as early retirement, avoidance of stress, and changes in diet. For some people such advice may be correct since it may make them happier, but there is no good evidence that it improves the prognosis for the majority. As in the primary prevention of coronary disease, we can confidently condemn smoking. ${ }^{7}$ Advice on increasing exercise for those without limiting angina or heart failure may now be added to the condemnation of tobacco, not for a reduction in mortality, which remains uncertain, but for improvement in the sense of wellbeing which is frequently so lacking after a heart attack.

Peter Carson

Consultant Cardiologist,

City General Hospital,

Stoke-on-Trent ST4 6QG

1 Morris JN. Exercise, health, and medicine. $B r$ Med 7 1983;286:1597-8.

2 Smith T. Exercise: cult or cure-all ? Br Med f 1983;286:1637-9.

${ }^{3}$ Carson $\mathrm{P}$, Phillips R, Lloyd M, et al. Exercise after myocardial infarction: a controlled trial. $7 R$ Coll Physicians Lond 1982;16:147-51.

4 Shephard RJ. The value of exercise in ischemic heart disease: a cumulative analysis. Fournal of Cardiac Rehabilitation 1983;3:294-8.

5 Oakley CM. After the infarct. Br.Med f 1983;287:625-6.

- Petch MC. Coronary bypasses. Br Med f 1983;287:514-6.

7 Mulcahy R. Influence of cigarette smoking on morbidity and mortality after myocardial infarction. Br Heart $\mathcal{F} 1983 ; 49: 410-5$.

\section{Treatment of acute stroke}

It is naive to expect that a single treatment will be appropriate for the different varieties of stroke, but certain principles of management may be applied. All but the mildest cases and patients who are moribund require admission to hospital, where careful clinical and laboratory assessment should be carried out. Too much emphasis has been placed on the need for computed tomography to differentiate between cerebral haemorrhage and infarction. This differentiation seldom alters management, and so routine scanning is unnecessary.

The core of the infarct or haemorrhage is damaged irreversibly, so that treatment should aim at preserving the cells in the surrounding ischaemic "penumbra," thereby minimising cerebral damage and subsequent handicap. Blood flow is negligible to the core of the stroke and poor to the penumbra, ${ }^{1}$ and cells which have vigorous metabolising activity are vulnerable when flow is reduced. It would seem appropriate, therefore, to reduce metabolism and improve cerebral blood flow. Neuronal metabolism may be reduced by sedative drugs or by hypothermia. The dose of sedative drugs needs to be high, however, and patients treated in this way may need ventilatory or circulatory support or both. ${ }^{2}$ Sustained hypothermia is also hazardous, especially in the elderly. The practical disadvantages of both of these techniques thus outweighs their potential advantages. Hypermetabolism during fits is damaging and must be suppressed immediately with parenteral anticonvilsants. ${ }^{3}$ Similarly if a patient becomes feverish antibiotics and simple techniques to reduce the temperature are indicated.

An increase in cerebral blood flow is difficult to achieve because the blood vessels in the penumbra are damaged and unresponsive to physiological or pharmacological stimuli. Vessels elsewhere in the brain may, however, respond normally. Paradoxically this may have an adverse effect, because when they dilate relatively more blood will be directed away from the area of need (intracerebral steal). Several drugs previously advertised as vasodilators have therefore been redesignated "metabolism improvers," but there is no convincing evidence that any of them are beneficial. Theoretically it would seem more appropriate to use drugs which cause vasoconstriction and those which suppress metabolism, although vasoconstrictor treatment, including low $\mathrm{PaCO}_{2}$, has not been shown to be of value.

Blood flow may also be increased by raising blood pressure, lowering intracranial pressure, haemodilution, or removing the arterial obstruction. Hypotension is unusual after a stroke, but relatively low pressures-for example, $120 / 80 \mathrm{~mm} \mathrm{Hg}$ in a hypertensive patient-may occur. Raising the blood pressure in such patients may restore flow and reduce cerebral ischaemia. ${ }^{4}$ Hypertension is common after a stroke. ${ }^{5}$ Often this is a temporary reflex phenomenon which helps to maintain flow despite the occluded vessels and raised intracranial pressure. Reducing blood pressure lessens the flow and may thus be counterproductive. ${ }^{6}$ In rare cases the blood pressure remains extremely high and leads to increasing cerebral oedema and raised intracranial pressure. Under these circumstances a cautious reduction in systolic blood pressure to about $180 \mathrm{~mm} \mathrm{Hg}$ is advisable, combined with an attempt to reduce intracranial pressure. This may be achieved by tilting patients with their heads up and ensuring that they are not overloaded with fluids. Steroid treatment may help in some cases, and glycerol, ${ }^{7}$ which is probably underused, is preferable to mannitol. ${ }^{8}$ The value of non-osmotic diuretics is questionable.

Reducing the packed cell volume lowers the oxygen carrying 
capacity of the blood but increases its flow. The optimal volume for delivery of oxygen is $0.42(42 \%),{ }^{9}$ so that in patients with a volume of over 0.45 (provided that this is not due to dehydration) it may help to lower the volume by haemodilution. ${ }^{10}$

Attempts to clear blocked cerebral vessels surgically have an unacceptable morbidity. Systemic thrombolytic techniques are also unsatisfactory, but administration of thrombolytic agents locally by a catheter may help. Surgery to anastomose extracranial and intracranial vessels is unlikely to help in the management of acute stroke. Surgery has a limited role in the management of cerebral and cerebellar haemorrhage. ${ }^{11}$ Provided that the patient's condition is stable, it is advisable to adopt a conservative approach, and surgical evacuation of the clot is indicated only if there is clinical deterioration and the haematoma is superficial.

The paper by Walshaw and Pearson ( $p$ 15) emphasises the importance of hypoxia in stroke. In cerebral ischaemia there is no shortage of glucose but a lack of oxygen and increased production of lactate and toxic free radicals. Every effort to improve oxygenation should be made by clearing the airway, giving oxygen, and physiotherapy. Further advantages may come from improving the oxygen carrying capacity of plasma and by improving the release of oxygen from haemoglobin. ${ }^{12}$ Hyperbaric oxygen may produce a temporary improvement.

A high blood glucose concentration is probably harmful. ${ }^{13}$ Studies have shown that raising blood glucose concentrations enlarges infarcts. Possibly lowering a raised glucose value will therefore reduce tissue acidosis and improve the prognosis. Disturbances in the concentration of the electrolytes and $\mathrm{pH}$ are common and need to be corrected.

Several drugs have been used to treat patients with acute stroke, but the few studied in carefully controlled trials have proved ineffective. Some false negative results are likely, however, because the numbers studied have often been too small to show even a 50\% benefit. Anticoagulants are not used except in patients with cerebral emboli which have originated from the heart. ${ }^{14}$ From $10 \%$ to $15 \%$ of such patients may have a further embolism within a few weeks. The risk of bleeding (provided that computed tomography shows no haemorrhage) is low and treatment with intravenous heparin is advised to inhibit the formation of further emboli. Deep vein thrombosis accurs in $30 \%$ of strokes ${ }^{15}$ and may be prevented by "antithrombotic" stockings and subcutaneous heparin. The value of antiplatelet agents has not been established.

Good management aims at preventing both the early and late complications of stroke. Thus it may be necessary to pass a nasogastric tube in the early stages to prevent aspiration. Later complications such as bedsores, contractures, and exposure keratitis should be avoidable with skilled nursing. Unfortunately, many patients still develop a painful shoulder from faulty lifting techniques and allowing the paralysed arm to hang. This may be prevented by passive physiotherapy and correct posturing; on the other hand, premature attempts to mobilise a patient are not likely to be helpful and may actually be harmful.

In conclusion there is no dramatic treatment for stroke, but the factors that make patients worse are now recognised. The mainstay of management is to maintain normal values of the blood gases, $\mathrm{pH}$, electrolytes, packed cell volume, and glucose and ensure fluid balance. A low blood pressure should be raised and all but severe, sustained hypertension temporarily ignored. Reduction of cerebral oedema by raising the head and giving glycerol or steroids or both may be attempted. Any fever or convulsion should be treated promptly. Finally, we must consider the spouse, whose loss and suffering are likely to be great; and many will go through a phase of critical resentment, which needs to be handled with understanding and tact.

\section{J THOMAS}

Senior Lecturer,

Institute of Neurology, and

Consultant Neurologist,

St Mary's Hospital,

London W2 1NY

${ }^{1}$ Wise RJS, Bernardi S, Frackowiak RSJ, Legg NJ, Jones T. Serial observations on the pathophysiology of acute stroke. Brain 1983;106: 197-222.

${ }^{2}$ Safar P. Amelioration of post-ischemic brain damage with barbiturates. Stroke 1980;11:565-8.

${ }^{3}$ Louis S, McDowell F. Epileptic seizures in nonembolic cerebral infarction. Arch Neurol 1967;17:414-8.

${ }^{4}$ Hope DT, Branston NM, Symon L. Restoration of ne'rological function with induced hypertension in acute experimental cerebral ischaemia. Acta Neurol Scand 1977;56, suppl 64:506-7.

${ }^{5}$ Wallace JD, Levy LL. Blood pressure after stroke. $\mathcal{f} A M A 1981 ; 246$ : 2177-80.

${ }^{6}$ Meyer JS, Shimazu K, Fukuuchi Y, et al. Impaired neurogenic cerebrovascular control and dysautoregulation after stroke. Stroke 1973;4: 169-86.

${ }^{7}$ Antonini FM, Bertini G, Fumagalli C, et al. Effects of intravenous infusion of glycerol on regional cerebral blood flow in cerebral infarction. Gerontology 1977;23:376-80.

${ }^{8}$ Johnston IH, Harper AM. The effect of mannitol on cerebral blood flow. An experimental study. $\mathcal{F}$ Neurosurg 1973;38:461-71.

${ }^{9}$ Kusunoki M, Kimura K, Nakamura M, et al. Effects of hematocrit variations on cerebral blood flow and oxygen transport in ischemic cerebrovascular disease. Fournal of Cerebral Blood Flow and Metabolism $1981 ; 1: 413-7$.

10 Wood JH, Fleischer AS. Observations during hypervolemic hemodilution of patients with acute focal cerebral ischemia. $f A M A 1982 ; 248$ : 2999-3004.

${ }^{11}$ Ojemann RG, Heros RC. Spontaneous brain hemorrhage. Stroke 1983; $14: 468-75$.

12 Perutz MF, Poyart C. Bezafibrate lowers oxygen affinity of haemoglobin. Lancet 1983 ;ii :881-2

${ }^{13}$ Fuller JH, Shipley MJ, Rose G, Jarrett RJ, Keen H. Mortality from coronary heart disease and stroke in relation to degree of glycaemia: the Whitehall study. $B r$ Med 7 1983;287:867-70.

14 Easton JD, Sherman DG. Management of cerebral embolism of cardiac origin. Stroke 1980;11:433-42.

${ }_{15}$ Warlow C, Ogston D, Douglas AS. Deep venous thrombosis of the legs after strokes. Part II-natural history. Br Med F 1976;i:1181-3.

\section{Genetic epidemiology in medicine-recent twin research}

The study of twins is attractive to clinical epidemiologists and geneticists because of its ability to unravel difficult issues of causality. Such studies may help determine a genetic predisposition for a disease by studying concordance rates in identical and fraternal twins, and may delineate environmental effects in pairs of twins where only one member of the pair has the disease or trait in question (the cotwin control method). Clinicians are by now familiar with the possibilities held out by the classical twin method but are less aware of the ability of the twin method not only to detect genetic effects but also to detect two particular types of environmental sources of variation-the common environment and the specific environment effects. ${ }^{1}$

The common environment effect is the effect on a trait or disease produced by family behaviour independent of genetic 